Chapman University

Chapman University Digital Commons

New Working Group: Teaching Mathematics for Social Justice in the Context of University Mathematics Content and Methods Courses

Eva Thanheiser

Frances K. Harper

Christa Jackson

Naomi Jessup

Crystal Kalinec-Craig

See next page for additional authors

Follow this and additional works at: https://digitalcommons.chapman.edu/education_articles

Part of the Curriculum and Social Inquiry Commons, Higher Education Commons, and the Science and Mathematics Education Commons 


\section{New Working Group: Teaching Mathematics for Social Justice in the Context of University Mathematics Content and Methods Courses}

\section{Comments}

This article was originally published in Mathematics Education Across Cultures: Proceedings of the 42nd Meeting of the North American Chapter of the International Group for the Psychology of Mathematics Education, Mexico in 2020. https://doi.org/10.51272/pmena.42.2020-18

\section{Copyright}

The authors

\section{Authors}

Eva Thanheiser, Frances K. Harper, Christa Jackson, Naomi Jessup, Crystal Kalinec-Craig, Cathery Yeh, and Amanda Sugimoto 


\section{NEW WORKING GROUP: TEACHING MATHEMATICS FOR SOCIAL JUSTICE IN THE CONTEXT OF UNIVERSITY MATHEMATICS CONTENT AND METHODS COURSES}

\author{
Eva Thanheiser \\ Portland State University \\ evat@pdx.edu \\ Naomi Jessup \\ Georgia State University \\ njessup@gsu.edu
}

\author{
Frances K Harper \\ University of Tennessee, Knoxville \\ francesharper@utk.edu \\ Crystal Kalinec-Craig \\ University of Texas, San Antonio \\ crystal.kalinec-craig@utsa.edu \\ Amanda Sugimoto \\ Portland State University \\ Asugimoto2@pdx.edu
}

\author{
Christa Jackson \\ Iowa State University \\ jacksonc@iastate.edu \\ Cathery Yeh \\ Chapman University \\ yeh@chapman.edu
}

\section{Goals:}

There are three goals for this new working group: 1) To create a community of mathematics teacher educators (MTEs) who are (or are interested in) collaboratively teaching mathematics for social justice (TMfSJ) in their university content and/or methods classes. 2) To collaboratively select/develop/modify TMfSJ tasks and implement those in mathematics content/methods classes. 3) To research the implementation of TMfSJ tasks in content and methods classes.

\section{Strategies to Reach Those Goals:}

The organizers have all (to some level) incorporated TMfSJ into their teaching. At a recent workshop, many of the organizers collaborated on designing one task to implement in both content and methods courses focused on understanding gentrification across the United States and also locally in each collaborator's own city/area. This collaboration was highly beneficial and led us to envisioning this working group. Our goal is to create a community of MTEs who will collaboratively develop and implement TMfSJ tasks in their university courses and research the implementation for (in no particular order): (a) preservice teacher (PT) learning about the mathematics, (b) PT learning about the sociopolitical context, (c) impacts 'on PTs' view of mathematics and/or teaching mathematics, and (d) the potential for TMfSJ in university methods or content courses to ignite a call for action.

\section{Background:}

Children and youth in schools today are increasingly aware of and grapple daily with the social injustices that pervade our world. Mathematics educators face a moral and ethical imperative to support students in their struggles to make sense of and fight against these injustices (Stinson, 2014). Incorporating social issues into the mathematics curriculum offers one way to both deepen students' mathematics knowledge and encourage the application of mathematics to understand and potentially change their world (Frankenstein, 2009). The Teaching Mathematics for Social Justice framework (TMfSJ) includes two critical interrelated ideas. First, school mathematics can be used to teach and learn about issues of social and economic justice. Second, mathematics can be taught through the study of social justice issues - the development of mathematical literacy itself being an important social justice issue (Gutstein, 2003; Raygoza, 2016). A growing body of research shows how TMfSJ lessons can support PK-12 students to learn mathematics, interrogate social justice issues, and deep positive mathematics identities (e.g. Chao \& Marlowe, 2019; Esmonde, 2014; Gutstein, 2003; Turner, Gutiérrez, Simic-Muller, \& Díez-Palomar, 2009). 
New Working Group: Teaching mathematics for social justice in the context of University Mathematics Content and Methods courses

Given the power of TMfSJ with PK-12 students, some MTEs seek to integrate TMfSJ tasks into their courses in order to give PTs, who have little or no experience with TMfSJ, opportunities to experience integrated learning of mathematics and social issues and to consider the relevance of TMfSJ to their local communities and instructional possibilities in their future classrooms. Research on TMfSJ in mathematics teacher education tends to focus on PT or teacher learning about the pedagogical conceptions and practices of TMfSJ (e.g. Bartell, 2013; Jong \& Jackson, 2016). PTs, however, also need opportunities to develop mathematical knowledge (Ball, Thames, \& Phelps, 2008) and political knowledge (Gutiérrez, 2017) for teaching mathematics generally and to enact TMfSJ, specifically. Little attention has been paid to the potential for TMfSJ in mathematics content and methods courses impact PTs' mathematics learning, understanding of social issues, and mathematics identities as well as their teaching practices. In other words, we seek to develop a research program that explores PTs learning not only about TMfSJ but also through TMfSJ.

Given the complexity of social issues and the challenge of using mathematics in authentic ways, TMfSJ proves more effective through multiple iterations over time (Harper, 2019). Accordingly, TMfSJ with PTs cannot happen in a single class. Instead, we seek to explore these ideas across content and methods courses at multiple spaces so that we can describe the complexity of these and other issues with our future teachers (and hopefully with their future students). This is especially true for content courses which allow elementary PTs to experience such tasks from a learner's perspective and to learn to read and write the world themselves. PTs can then build upon this in methods courses to explore the pedagogical practices for TMfSJ.

Many PTs enter their coursework believing that mathematics is neutral or universal (Greer, Verschaffel, \& Mukhopadhyay, 2007; Keitel \& Vithal, 2008). MTEs must address the fact that mathematics can never be neutral and no classroom is a neutral space (Frankenstein, 1983; Gutiérrez, 2013; Yeh \& Otis, 2019).TMfSJ offers a means of engaging PTs in building their sociopolitical consciousness about the political implications of mathematics and how math can be leveraged to read and write the world (Gutstein \& Peterson, 2005) from both a content and teaching methods perspective.

In some cases MTEs have met resistance from PTs when integrating social justice issues into the mathematics curriculum (Aguirre, 2009; Ensign, 2005; Felton-Koestler, Simic-Muller, \& Menéndez, 2012; Rodríguez \& Kitchen, 2004). However, MTEs have also found that they are able to broaden PTs' perspectives about mathematics and mathematics teaching (Bartell, 2013; Ensign, 2005; Felton \& Koestler, 2015; Leonard \& Moore, 2014; Mistele \& Spielman, 2009) when PTs are given opportunities to engage in TMfSJ tasks during teacher preparation. This aligns with Gutstein's (2003) goal of supporting students in developing their sociopolitical consciousness, and possibly a stronger sense of agency and identity. Given the possibilities for TMfSJ to impact both PT and PK12 student learning and mathematics identity in similar ways, PME-NA offers an ideal community for spearheading this work by bringing together experts in both student and teacher learning.

\section{Participant Engagement}

Session 1: Successes and struggles implementing TMfSJ tasks: 1) Organizers will present (30 minutes) on how they have used TMfSJ tasks in their classrooms. 2) Participants and organizers discuss the successes and struggle in implementing TMfSJ tasks. 3) Towards the end of the session, organizers will introduce one context to focus on for the next two sessions (e.g. gentrification) as well as an online media platform for continued participation with this group.

Session 2: Entry points for TMfSJ tasks: 1) We will discuss various entry points (focus on math and social issue) for TMfSJ tasks. 2) We will collaboratively engage in the use of one context in our classes and potential tasks that could go with that context. 3) Participants will share their own experiences and how they may envision using such a context in their class. 
New Working Group: Teaching mathematics for social justice in the context of University Mathematics Content and Methods courses

Session 3:1) We (in small groups) will collaboratively create/adapt TMfSJ task(s) to participants' localized contexts to use in their teaching. Participants will leave with a more nuanced understanding of TMfSJ tasks/implementation. 2) We will set up structures to follow up via online media after implementations. 3) The goal will be to meet at next year's PME-NA.

\section{References}

Aguirre, J. M. (2009). Privileging mathematics and equity in teacher education: Framework, counter-resistance strategies and reflections from a Latina mathematics educator.

Ball, D., Thames, M. H., \& Phelps, G. (2008). Content knowledge for teaching: What makes it special? Journal of Teacher Education, 59(5), 389-407.

Bartell, T. G. (2013). Learning to teach mathematics for social justice: Negotiating social justice and mathematical goals. Journal for Research in Mathematics Education, 44(1), 129-163.

Chao, T., \& Marlowe, M. M. (2019). Elementary Mathematics and\# BlackLivesMatter. Occasional Paper Series, 2019(41), 9.

Ensign, J. (2005). Helping teachers use students' home cultures in mathematics lessons: Developmental stages of becoming effective teachers of diverse students. In A. J. Rodriguez \& R. S. Kitchen (Eds.), Preparing mathematics science teachers for diverse classrooms: Promising strategies for transformative pedagogy (pp. 225-242). Mahwah, NJ: Lawrence Erlbaum Associates.

Esmonde, I. (2014). “Nobody's rich and nobody's poor ... It sounds good, but it's actually not": Affluent students learning mathematics and social justice. Journal of the Learning Sciences, 23(3), 348-391. doi:10.1080/10508406.2013.847371

Felton, M. D., \& Koestler, C. (2015). "Math Is All Around Us and... We Can Use It to Help Us": Teacher Agency in Mathematics Education Through Critical Reflection. The New Educator, 11(4), 260-276.

Felton-Koestler, M. D., Simic-Muller, K., \& Menéndez, J. (2012). Math isn’t just numbers or algorithms”: Mathematics for social justice in preservice K-8 content courses. In Mathematics teacher education in the public interest: Equity social justice (pp. 231-252).

Frankenstein, M. (1983). Critical mathematics education: An application of Paulo Freire's epistemology. Journal of Education, 315-339.

Frankenstein, M. (2009). Developing critical mathematical numeracy through real real-life word problems. In L. Verschaffel, B. Greer, W. Van Dooren, \& Mukhopadhyay (Eds.), Words and worlds: Modeling verbal descriptions of situations (pp. 111-130). Boston, MA: Sense Publishers.

Greer, B., Verschaffel, L., \& Mukhopadhyay, S. (2007). Modelling for life: Mathematics and children's experience. In Modelling and applications in mathematics education (pp. 89-98): Springer.

Gutiérrez, R. (2013). The sociopolitical turn in mathematics education. Journal for Research in Mathematics Education, 44(1), 37-68.

Gutiérrez, R. (2017). Political conocimiento for teaching mathematics. Building support for scholarly practices in mathematics methods, 11 .

Gutstein, E. (2003). Teaching and learning mathematics for social justice in an urban, Latino school. Journal for Research in Mathematics Education, 34(1), 37-73. doi:10.2307/30034699

Gutstein, E., \& Peterson, B. (2005). Rethinking mathematics: Teaching social justice by the numbers: Rethinking Schools.

Harper, F. K. (2019). Collaboration and Critical Mathematical Inquiry: Negotiating Mathematics Engagement, Identity, and Agency. Occasional Paper Series, 2019(41), 5.

Jong, C., \& Jackson, C. (2016). Teaching mathematics for social justice: Examining preservice teachers' conceptions. Journal of Mathematics Education at Teachers College, 7(1).

Keitel, C., \& Vithal, R. (2008). Mathematical power as political power-the politics of mathematics education. In Critical issues in mathematics education (pp. 167-188): Springer.

Leonard, J., \& Moore, C. M. (2014). Learning to enact social justice pedagogy in mathematics classrooms. Action in Teacher Education, 36(1), 76-95.

Mistele, J. M., \& Spielman, L. J. (2009). Engaging Preservice Teachers in Mathematics: Social Analysis in the Mathematics Classroom. Democracy Education, 18(3), 64-67.

Raygoza, M. C. (2016). Striving toward Transformational Resistance: Youth Participatory Action Research in the Mathematics Classroom. Journal of Urban Mathematics Education, 9(2), 122-152.

Rodríguez, A. J., \& Kitchen, R. S. (2004). Preparing mathematics and science teachers for diverse classrooms: Promising strategies for transformative pedagogy: Routledge. 
New Working Group: Teaching mathematics for social justice in the context of University Mathematics Content and Methods courses

Turner, E. E., Gutiérrez, M. V., Simic-Muller, K., \& Díez-Palomar, J. (2009). "Everything is math in the whole world": Integrating critical and community knowledge in authentic mathematical investigations with elementary Latina/o students. Mathematical Thinking and Learning, 11(3), 136-157.

Yeh, C., \& Otis, B. M. (2019). Mathematics for Whom: Reframing and Humanizing Mathematics. Occasional Paper Series, 2019(41), 8. 